\title{
ARQUITETURA ESCOLAR: CURRÍCULO OU CURRAL?
}

\section{SCHOOL ARCHITECTURE: ARQUITECTURE AS CURRICULUM OR "ENCLOSURE"?}

\author{
Prof.Dr. Enéas Arrais Neto ${ }^{1}$ \\ Diego Enéas Peres Ricca ${ }^{2}$ \\ Prof. Dr. Raphael Pires de Souza ${ }^{3}$
}

\section{RESUMO}

A Arquitetura Escolar é muito pouco estudada tanto nos cursos de arquitetura quanto na formação dos educadores, nos cursos de pedagogia. Os estudos e publicações sobre arquitetura escolar disponíveis são em sua maioria focados nos aspectos eminentemente técnicos, e a relação da arquitetura escolar com o processo pedagógico que ocorre nesse espaço é abordada apenas referindo-se ao ensino infantil. $\mathrm{O}$ arquiteto em seu ato de projetar constitui-se também como educador. Suas opções e escolhas podem colaborar para o desenvolvimento educacional e refletem sua concepção curricular, e do papel da escola na sociedade. A arquitetura escolar, assim, pode ser parceira e componente de um currículo emancipador. Em suma, para cada projeto político pedagógico escolar corresponde uma ou algumas concepções específicas de arquitetura - eis a questão que tem passado em branco nas discussões tanto na área de arquitetura quanto na de educação-pedagogia.

PALAVRAS-CHAVE: Arquitetura Escolar - Currículo - Formação Humana Omnilateral.

\begin{abstract}
The issue of School Architecture has been neglected in general, both in theoretical studies of architecture and training of architects, as in the training of educators. Studies on school architecture are mostly focused on highly technical aspects and its relationship to the educational process are addressed, in part, only for a given age group - children's education. The architect in his act of designing constitutes space and school building as an educator. His options and choices can contribute to the educational


development and reflect their curricular design, the school's role in society. School architecture, so can be dialectically partner and component of an emancipatory curriculum. Each pedagogical political project represents one or a few specific conceptions of architecture - that is the question that has passed unnoticed in discussions both in architecture and in education-pedagogy.

KEYWORDS: School Architecture; Curriculum; Human Formation Omnilateral

\section{INTRODUÇÃO}

A problemática da Arquitetura Escolar foi negligenciada, de maneira geral, tanto nos estudos teóricos de arquitetura e na formação dos arquitetos, quanto no processo de formação dos educadores, tendo repercussão na forma como o sistema escolar brasileiro pouco ou nada discutiu da relação pedagógica do espaço escolar e da importância educativa da edificação e de sua concepção arquitetônica. Enfocada apenas quando do desenvolvimento de arquitetura escolar para a educação infantil ou, no máximo de ampliação, da concepção de espaços escolares destinados à primeira etapa do ensino fundamental (primeiro ao quinto ano), a compreensão assentada tanto nas secretarias de educação (estados e municípios) quanto no senso comum da área de educação e pedagogia parece limitar a relação entre currículo e arquitetura ao espaço voltado à educação de crianças.

Esta percepção genérica reflete, não intencionalmente a concepção de que somente as crianças merecem definições espaciais específicas. Esta especificidade é percebida principalmente a partir do caráter ergonômico do espaço a elas destinado, ficando muito claro e evidente para qualquer pessoa de mínimo bom-senso que o dimensionamento dos espaços e equipamentos infantis é diferenciado, em relação ao dos demais membros de outras faixas etárias.

De forma pouco nítida ou pouco pedagogicamente deliberada, mas mesmo assim muito superior a equipamentos voltados a outras faixa-etárias, os espaços de ensino infantil mostram preocupações de ordem humanista centradas numa concepção de infância como tempo id́lico, que permitiria (ainda) a vivência dos aspectos lúdicos da vida, ao lado ao qual da incorporação de elementos naturistas de presença de jardins no 
espaço infantil e adequação das salas de aula a atividades de cunho coletivo, com alguma (pequena) referência aos projetos pedagógicos específicos a que a escola em questão se filia - Montessori; Waldorf; Reggio Emilia; Construtivismo, dentre outros - e suas diferentes concepções curriculares.

Nos casos de faixas-etárias posteriores, nas quais os estudantes têm condições ergonômicas eminentemente similares a dos adultos, os projetos escolares caem na valacomum da desconsideração da diversidade de mobilidade, potência, habilidades etc, condicionadas pelas variações orgânicas e corporais dos indivíduos ao longo de suas vidas. O que se percebe é um nítido esquecimento da importância dos aspectos físicos e ambientais no espaço de aprendizado, onde ricas propostas pedagógicas aliadas a estudos aprofundados na teoria do ensino e aprendizagem, poderiam potencializar a relação do estudante-aprendiz com o ambiente escolar e qual seria a forma arquitetônica ideal para cada abordagem de ensino.

Nas pesquisas educacionais brasileiras, a arquitetura, de fato, pouco se faz presente, apresentando-se de forma apenas descritiva, realizando uma análise muito mais espacial concreta do que subjetiva e simbólica (Moussatché, 1998). A questão da arquitetura escolar, assim, fica reduzida à mera solução técnica de dimensionamentos ergonômicos e ergométricos do espaço, da utilização de materiais e soluções arquitetônicas de razoável nível de acabamento e facilidade de manutenção. No máximo, nas últimas décadas, se incorporou as questões da acessibilidade e sustentabilidade energética e ecológica. Estas últimas, mesmo que de forma incipiente, trouxeram alguns elementos de avanços, conquanto submetidos a uma perspectiva eminentemente técnica, desconhecendo possibilidades de utilização pedagógica das edificações e espaços escolares. Há, portanto, uma nítida separação entre os aspectos técnicos da arquitetura escolar e da sua respectiva orientação curricular pedagógica.

Do arquiteto projetista da escola espera-se que, além da solução das questões técnicas de funcionalidade, ergometria, iluminação e conforto térmico, apresente uma solução arquitetonicamente "bela" dentro da estética comumente difundida pela Indústria Cultural. Essa estética intencionalmente produzida expressa os ideais de beleza, modernidade, contemporaneidade, funcionalidade e boa técnica, definidos a partir de padrões históricos que refletem aspectos do momento (moda) e da cultura de cada setor de classe social. Incorporam, inconscientemente a referência ideológica implícita no referencial formativo de arquitetos e educadores que, atualmente, reflete padrões que mesclam tecnicismo, reprodução cultural e controle disciplinar não 
claramente definidos e supostamente não postulados por esses mesmos educadores e arquitetos.

O que nosso estudo pretende apontar como referencial para a práxis arquitetônica voltada para os espaços escolares é que o arquiteto transcenda os quesitos técnicos básicos, explorando ao máximo o que a arquitetura tem a contribuir para o campo da educação, permitindo que esta seja estudada, continuamente, pela sensibilidade e racionalidade, pois carrega "características não só físicas, mas também simbólicas, na medida em que haja um reconhecimento das significações nele contidas". (MOUSSATCHÉ, 1998, p.20-21). Na medida que haja, portanto, uma aliança entre projeto e currículo.

\section{ARQUITETURA, CURRÍCULO, CORRA E CURRAL}

Ora, toda escola tem como base e centro de seu trabalho o desenvolvimento de uma concepção curricular. Esta concepção curricular reflete um modelo formativo. Expressa um referencial pedagógico baseado em visões de mundo, de sociedade e de ser humano que se pretende desenvolver. Sintetizado no que se compreende como currículo, o projeto de formação de pessoas definido pela escola como instituição formativa na realidade brasileira expressa elementos históricos e culturais cujos conteúdos são elaborados a partir das perspectivas da cultura burguesa, hegemônica em nossa realidade. Inclui, sob esse amplo "guarda-chuva" ideológico, aspectos da cultura massificada pela mídia, produzidos pela indústria cultural, reproduzindo modelos de dominação cultural dos setores dominantes. Por outro lado, como emergência dialética das contradições dessa mesma sociedade de classe, apresenta ao observador com bom referencial teórico-analítico, não menos importantes aspectos de resistência e luta dos setores subalternos, manifestos geralmente sob a forma de insubmissão, revolta e malestar estudantil nos espaços de confinamento escolar.

A expressão de resistência perceptível no desconforto estudantil com os espaços escolares é um claro sinal de uma arquitetura pensada e desenvolvida a partir de referenciais claramente disciplinadores centrados nas ideias de disciplina, controle, obediência e submissão. O desgosto e negação da escola perceptíveis nas atitudes e posturas dos adolescentes e da juventude, que se expressa como negação e recusa à utilização dos espaços e equipamentos educativos supostamente destinados a sua 
formação é reflexo claro de desencontros de perspectivas geracionais e da negação aos instrumentos de controle representados no espaço e arquitetura escolares. Tal descontentamento e resistência refletem-se também no desconforto cotidiano de educadores interessados em projetos pedagógicos alternativos, incomodados com a dificuldade de desenvolvimento de atividades de cunho mais autônomo ou livre nos edifícios escolares de arquitetura tradicional ou, mesmo, naqueles desenvolvidos a partir de projetos tidos como modernos, contemporâneos e inovadores.

Tal negação ao espaço escolar nos leva a uma importante compreensão que devemos salientar é a de que a noção de espaço é estritamente ligada à noção de tempo. O espaço vivenciado é elemento construtor e articulador de nossas memórias, sendo assim articulador de identidades e referenciais de vida. A respeito disso Frago (2001, p.63) afirma que "são muitas as influências e entrecruzamentos entre o espaço e o tempo". A própria noção de memória que temos é fruto da "recordação de espaços diversos ou de fixações diferentes de um mesmo espaço". A memória é, em suma, um depósito de imagens e sensações decorrentes da relação com o espaço, que, por fỉm, se tornaram lugares, "Lugares nos quais algo de nós ali ficou e que, portanto, nos pertencem; que são, portanto, nossa história" (FRAGO, 2001, p.63). Por isso, o espaço "não é um meio objetivo dado de uma vez por todas, mas uma realidade psicológica viva” (MESMIN, 1973, p.16 apud, FRAGO, 2001, p.63).

É por conta disso que os espaços de ensino devem ser pensados com tanta atenção e cuidado, pois estes ficarão marcados para sempre na memória dos que ali frequentaram. As vivências que possibilitam, os comportamentos que induzem, as ideações que estimulam, bem como as vivências que dificultam ou impedem, a autonomia que queda constrangida, o protagonismo cerceado $\mathrm{e}$ as ideias que reproduzem, são determinantes elementos da formação da personalidade, da cultura e da visão de mundo de seus usuários, sejam eles estudantes, professores ou quaisquer outros que vivenciem a edificação. E esta relação afetiva, emocional, inconsciente, com o meio educacional, se propositalmente articulada com um referencial pedagógico, é essencial para estruturar e estimular a relação do estudante com o espaço da escola. Said (2007) exemplifica essa ligação afetiva ao falar de como crianças que experimentam passar mais de dois dias em um jardim de hospital tendem a criar um sentimento de afeto e pertencimento a esse espaço, o que faz com que elas queiram voltar a esse local se elas ficarem doentes novamente. 
Em suma, se uma experiência em um espaço levar a um sentimento de satisfação e alegria, essa experiência fica na memória, da mesma forma se esse sentimento for ruim e insatisfatório, pode fazer com que um aluno não sinta vontade de voltar aquele espaço, pois ali suas memórias, e, portanto, sentimentos, não são bons e não transmitem prazer.

A arquitetura escolar, portanto, mantem uma vinculação direta com a noção de currículo, com a qual se vincula como elemento fundamental do desenvolvimento de atitudes, valores, concepções, visão de mundo etc. Mesmo que não observável aos olhares desatentos e superficiais, a edificação, sua concepção estética e seu espaço, são determinantes para o processo educativo implícito, psíquico, atitudinal, centrado em questões muitas vezes inconscientes, mas com rebatimento direto nas possibilidades conscientes da formação almejada. Assim, precisamos retornar à definição mesma de Currículo para que possamos entender alguns aspectos centrais da questão da arquitetura escolar, conforme pretendemos desenvolver.

\section{ARQUITETURA ESCOLAR TRADICIONAL E ARQUITETURA ESCOLAR CONTEMPORÂNEA COMO ARQUITETURA DE CORRA E CURRAIS}

Currículo: ETIM.Lat.curriculum,i - corrida, carreira, lugar onde se corre, campo, liça, hipódromo, picadeiro, do v.lat. currere; Corra - ato de correr, tira feita de couro para se prender, laçar alguma coisa, correia, verificação rápida feita com o olhar; Curral lugar cercado onde se prende e/ou recolhe gado ETIM orig. duv. Currale, is circo para corridas de carros, sin/variação bezerreiro, cercado, armadilha (HOUAISS, Antonio et VILLAR, Mauro S. Dicionário Houaiss da Língua Portuguesa. Rio de Janeiro, Editora Objetiva, 2001).

Efetivamente, as palavras da língua portuguesa: Currículo, Corra e Curral, têm origens similares na mesma base latina. Significando na nossa realidade elementos díspares, pedagogicamente diversos e até contraditórios, veremos que são esclarecedores de possibilidades interpretativas do papel da arquitetura escolar. Tudo o que acontece na escola é, de alguma forma, parte do Currículo nela vivenciado e 'percorrido' pelos estudantes, mas não somente por eles. Deve-se entender que o espaço escolar é vivenciado por todos os segmentos (e os indivíduos que os compõem) participantes da instituição escola. compreendendo estudantes, educadores, quadros 
técnicos da administração escolar, quadros de apoio e manutenção da edificação e de seu funcionamento, pais que a ela comparecem, e, inclusive, pessoas ou grupos da comunidade que eventualmente a frequentem para acontecimentos especiais ou reuniões regulares (grupos de idosos, AA, esportistas e outros).

Compreendemos que o currículo escolar é 'percurso' para todas essas pessoas que convivem diariamente nesse espaço institucional, desta forma, sendo elemento educativo implícito, transmitindo valores, concepções sociais e visões de mundo. Defendemos a compreensão de que as vivências cotidianas acontecidas em todo e qualquer espaço edificado, e na escola especificamente, são educativas, no sentido amplo da palavra - são comunicadoras e estabelecedoras de sentido dentro de um universo cultural. Aprendemos relações, concepções de mundo, de vida, perspectivas e formas de ver conteúdos ao vivenciar práticas dentro da escola, independente de em que 'categoria' e subgrupo escolar estamos incluídos.

A referência formativa da ideologia originária - contexto cultural simbólico geral da sociedade - cria códigos e sistemas de significação que permitem que inconscientemente nós decodifiquemos a mensagem que a arquitetura traz. Essa transmissão de sentido se dá a medida em que vivenciamos a arquitetura em nosso diaa-dia, num envolvimento físico-visual acompanhado do jogo da imaginação que nos relaciona às experiências vividas, a conteúdos culturais, científicos e ideológicos, e projeta significados compreensivos a partir de elementos que a arquitetura fornece: a forma dos prédios, sua arquitetura, seu estilo, seus espaços etc.

A arquitetura utiliza o espaço construído como meio de abrigar e transmitir sensações por meio de sua forma e função. Para um dos maiores teóricos da arquitetura, Bruno Zevi, "as quatro fachadas de uma casa (...) por mais belas que sejam, constituem apenas a caixa dentro da qual está encerrada a joia arquitetônica" (ZEVI, 2002, p.20). Arquitetura é, portanto, aquilo que possui espaço interno, que abriga o homem e suas variadas relações com o meio. Zevi em seguida esclarece:

(...) Dizer que o espaço interior é a essência da arquitetura não significa efetivamente afirmar que o valor de uma obra arquitetônica se esgota no valor espacial. Cada edifício caracteriza-se por uma pluralidade de valores: econômicos, sociais, técnicos, funcionais, artísticos, espaciais e decorativos (...). 
Dentro disso França (1994, p.13) diz que os ambientes arquitetônicos seguem uma estreita ligação com os valores de sua época, são "espelhos de inquietações sociais e espirituais, concretizadas em fachadas e disposições interiores". Posteriormente afirma que "As formas que o padrão arquitetônico assume não ocorrem desvinculadas das situações culturais, que por sua vez não estão desvinculadas da base material da sociedade". A análise crítica e interpretativa do sentido do espaço arquitetônico contribui para um resgate da subjetividade do homem, sendo o meio em seu entorno um fruto, tanto de sua base biológica como de sua cultura, orientação política, experiências crenças e valores. Como afirma Frago (2001, p. 64):

\begin{abstract}
(...) o espaço jamais é neutro: em vez disso, ele carrega, em sua configuração como território e lugar, signos, símbolos e vestígios da condição e das relações sociais de e entre aqueles que o habitam. O espaço comunica, mostra a quem sabe ler o emprego que o ser humano faz dele mesmo. Um emprego que varia em cada cultura; que é um produto cultural específico, que diz respeito não só a relações interpessoais - distâncias, território pessoal, contatos, comunicação, conflitos de poder -, mas também a liturgia e ritos sociais, à simbologia das disposições dos objetos e dos corpos - localização e posturas-, à sua hierarquia e relações.
\end{abstract}

Assim, quando aqui diferenciamos, as formas de Arquitetura Escolar como Currículo, Corra e Curral, apenas sob suas conotações particulares estamos dizendo que a Arquitetura Escolar pode ser expressão explícita de possibilidades, entre as quais uma vertente se demonstra como predominante. Como possibilidade, mas praticamente inexistente como exemplificação concreta e real, a arquitetura escolar pode ser parceira e componente de um currículo engrandecedor, com ela articulado e de cujos elementos propositais ela é parte constitutiva.

(...) evidente que as escolas do bosque ou os jardins de infância, para dar alguns exemplos, expressaram em sua institucionalização material as teorias que os legitimaram, como igualmente é notório que as escolas seriadas ou as classes de ensino mútuo refletiram as práticas didáticas que se abrigaram entre seus muros. (FRAGO, 2001, p. 26).

O arquiteto, como elaborador da edificação escolar é também um educador, cujos ensinamentos se transmitem através das formas que ele concebe e que constituem o entorno do aluno desde sua mais tenra idade. O espaço escolar não é um local neutro e sem influência no aprendizado, não é, segundo Frago (2001, p.26) 
(...) apenas um "continente" em que se acha a educação institucional, isto é, um cenário planificado a partir de pressupostos exclusivamente formais no qual se situam atores que intervêm no processo de ensino-aprendizagem para executar um repertório de ações.

A arquitetura escolar é, portanto, por si mesma, um programa. Nas teorias da percepção, o espaço-escola, é "um elemento significativo do currículo, uma fonte de experiência e aprendizagem" (FRAGO 2001, p.26) e pode ser considerada, segundo Mesmin (1967, p.62-66 apud, FRAGO, 2001, p.27) "uma forma silenciosa de ensino”, o que constitui o currículo oculto da "espacialização" do ensino.

Por outro lado, e representada na concepção de edifícios efetivamente existentes, a Arquitetura Escolar pode igualmente ser expressão de Corra ou 'laço' para prender, constituindo-se também numa espécie de Curral, lugar onde se prende e recolhe os estudantes, com a decorrente conclusão de que sejam abatidos politicamente e intelectualmente, em termos do desenvolvimento autônomo de suas personalidades. As diferentes possibilidades da Arquitetura Escolar podem leva-la a assumir uma ou outra função, desenvolver uma ou outra possibilidade. O mais grave: quando a Arquitetura Escolar não é claramente compreendida como parte de um projeto de Currículo (em seu sentido estrito de projeto pedagógico, com todas as implicações a ele articuladas) ela se constitui claramente como 'ferramenta' de construção de modelos curriculares assemelhados a Corra e Curral.

Dentro da compreensão difundida pela concepção corrente, não apenas massificada pela indústria cultural e sua mídia, mas inclusive numa perspectiva erudita (de profissionais de nível superior e da produção acadêmica a eles relatada), os projetistas da arquitetura escolar no Brasil têm buscado soluções técnicas e projetivas que modernizam as edificações, imprimindo-lhes um caráter adequado ao mundo industrial capitalista. Essa arquitetura significa uma ruptura clara com os modelos arquitetônicos anteriores, inspirados nos Conventos e Quarteis. Uns e outros, modernos e antigos, com clara influência e presença de mecanismos do 'Panóptico' de Jeremy Bentham.

Tendo tido a contribuição original das congregações e ordens religiosas, inicialmente masculinas e, a partir de meados do século XX, igualmente congregações femininas, a educação escolar brasileira teve quase, diríamos, naturalmente, determinações dos referenciais religiosos católicos. Os padres, frades e freiras, cuja formação se dava em conventos com arquitetura grandemente similar, independente de 
suas ordens, reproduziam em suas escolas a concepção do "Claustro", como forma necessária ao 'fechamento’ e ‘isolamento’ para o mundo, necessários em sua concepção educacional, centrada na disciplina, silêncio, controle dos movimentos, controle do corpo, controle atitudinal e reprodução cultural centrada na ideologia religiosa e na cultura clássica europeia. A forma geral dos grandes colégios católicos e os elementos específicos dessa arquitetura foram e ainda são instrumentos de transmissão de valores, conformam atitudes, maneiras de ser, de caminhar, de pensar e de se portar. Transmitem concepções de mundo, são agentes educativos importantes, conquanto inconscientes.

A primeira ruptura ou alternativa de matriz arquitetônica nos chegou com os ideais do positivismo, que ao final do século XIX trouxe ao país concepções de ciência, de progresso, de ordem social não religiosa, influências difundidas por setores médios urbanos e de forte penetração entre os militares brasileiros. Essa visão 'modernizadora', rompendo com a tradição escolástica da educação, levou à mudança relativa dos referenciais maiores dos prédios escolares, que passaram a ter nos quartéis sua influência emblemática, com pavilhões, áreas abertas, pátios, elementos cujo desenho e posicionamento refletem, não menos que os componentes de ordem e controle, ideais de racionalidade, higienismo e ciência.

Uns e outros (arquitetura escolar de referência religiosa ou de referência militar) incorporam aspectos defendidos e propostos no edifício prisional conhecido como o "Panóptico de Bentham". A prisão concebida pelo filósofo reformador inglês apresentava uma concepção de controle visual que buscava a auto-repressão dos próprios detentos, estabelecida através do medo. Bentham criticou a ideia de que se deveria ou conseguiria controlar os presos pela repressão externa permanente e direta por considera-la impossível de ser levada a cabo por um largo período. Como não se pode estar o tempo todo vigiando a todos para reprimi-los em todos os momentos de insubordinação, sugeriu, em lugar dessa tentativa, a construção de um processo de autorepressão pelo medo do controle e da observação possíveis a qualquer momento. Daí decorre a noção de Panóptico - que vê tudo, que vê todos.

O 'Panoptico de Bentham'é um edifício em que as celas são visíveis a qualquer momento, abertas para um pátio central em que numa torre fechada, os vigias não são visíveis. Dessa forma, nunca se sabe quando se está sendo observado, nem por quem se está sendo observado, além de que essa observação pode ocorrer a qualquer momento ou a todo momento, acrescentando o elemento surpresa, com a recorrente punição para qualquer ato infracional disciplinar. Do presídio também se herdou nas escolas, além 
das portas de sala com as pequenas aberturas para ser observado a qualquer momento, sem que se veja ou ouça a aproximação do 'bedel', do 'supervisor' ou 'coordenador' de alunos, outros elementos como as grades isolando setores, fechando-os e controlando acessos dos estudantes. De quarteis e presídios, herdou a escola um instrumento que se considera fundamental: uma escola funciona faltando professores, faltando carteiras, faltando água e luz, faltando livros - mas nunca falta a chamada. Esse elemento fundamental do controle disciplinar da presença foi acrescido do aspecto importantíssimo para o capitalismo industrial que é o controle do tempo e da pontualidade, expresso nas sirenes, sinetas, 'relógios de ponto, cadernetas de frequência entre outros elementos.

Por outro lado, o Panóptico pode ser uma máquina de fazer experiências, modificar comportamento, treinar e retreinar, podendo servir para "cuidar dos doentes, instruir os escolares, guardar os loucos, fiscalizar os operários, fazer trabalhar os mendigos e ociosos" (FOUCAULT, 1997, p.170). Isso é alcançado com uma simpes ideia arquitetural, sendo uma prova clara de como a forma arquitetônica pode ter influência positiva ou negativa na realidade dos seres humanos. Da mesma forma como uma disposição extremamente programada dos espaços de ensino pode gerar seres padronizados, controlados, alienados e conformados.

Mais recentemente, a partir dos anos 1980, no final do século passado, emerge uma nova referência para a arquitetura escolar, o espaço empresarial capitalista. A empresa capitalista é em sua essência um espaço industrial, de produção em grandes quantidades. Massificação e padronização ou massificação dentro de variedades controladas é um dos eixos de um processo em que a produtividade significa o elemento central gerador dos ganhos e lucros capitalistas, produzidos como mais-valia embutida nos produtos e serviços oferecidos aos consumidores.

Constrói, paralelamente, uma sociedade de massificação e controle, de consumo de massa, cujas ideias são difundidas por um setor especializado de seu aparelho institucional que as produz 'industrialmente' e as impinge reiteradamente através de um sistema de mídia televisiva, radiodifundida e escrita que é onipresente e diuturno. A escola e seu edifício são, neste sentido, elementos confirmadores e espaço de exercício desses valores de massificação, controle, obediência, consumo, submissão às estruturas e personificações do sistema social.

Essa estrutura ideológica subjacente à arquitetura escolar tem nas noções de racionalidade científica e técnica seu elemento central de justificação e respaldo. As 
plantas e edifícios ortogonais, prismáticos, quadrados, cubos, esferas, parábolas, são manifestações de linguagem racional, científica. Transmitem, ou retransmitem, de forma imanente, esse campo de compreensão do qual emergem. Esses edifícios são 'naturalmente' modernos e avançados aos olhos massificados e 'embaçados' pela ideologia originária que permeia toda a sociedade atual. São inquestionavelmente 'bons' ou 'boa arquitetura' na leitura dos arquitetos e das secretarias de educação que os recebem. Aliado a justificativas ergonômicas e ergométricas que definem dimensionamentos, passagens, circulações e formas dos ambientes, erigem um 'castelo inexpugnável' de conceitos no senso comum e na modelagem de edifícios escolares.

Queda obscurecida e inquestionada a matriz pedagógica favorecida por essa tipologia arquitetônica, assim como também permanecem obscurecidos os referenciais pedagógicos divergentes, dificultados - quase impedidos - por essas escolhas que aparentam ser apenas formais, mas que carregam em seu bojo conteúdos atitudinais, valorativos, ideias, conceitos, posturas induzidas, ações estimuladas e ações dificultadas. Arquitetura escolar a serviço e manifestação de controle, submissão, obediência, subserviência, massificação, ordem, heteronomia, em vez de espaço e edifícios voltados à autonomia, protagonismo, liberdade, ampliação cultural, desenvolvimento da personalidade, construção coletiva.

\section{CONSIDERAÇÕES FINAIS}

Os estudos sobre arquitetura escolar são em sua maioria focados nos aspectos eminentemente técnicos e sua relação com o processo pedagógico são abordados, em parte, apenas para uma dada faixa etária - ensino infantil. A referida temática, arquitetura escolar e currículo, acaba sendo negligenciada nos espaços de formação acadêmica seja no Curso de Arquitetura ou no Curso de Pedagogia.

Ergonomia, acessibilidade, materiais de acabamento, tecnologia construtiva, sustentabilidade energética, ecologia são alguns caminhos percorridos pelos estudos na área. A incipiência de estudos profundos sobre a utilização pedagógica do espaço e o espaço no processo educacional indiferente da faixa etária educacional, representa a separação entre a técnica arquitetônica e a orientação curricular pedagógica.

$\mathrm{O}$ arquiteto em seu ato de projetar constitui-se também como educador. Suas opções e escolhas podem colaborar para o desenvolvimento educacional e refletem sua 
concepção curricular, do papel da escola na sociedade. A construção do espaço escolar, assim, pode representar e constituir-se mais um instrumento de controle e de dominação cultural ou tornar-se o lócus para a construção do saber, da autonomia, da formação humana.

A negação ao espaço escolar, por parte dos alunos é, em parte, reflexo da negação do que a escola representa para estes em si. A arquitetura passa a ser vista muitas vezes como a materialização do corra e do curral, o espaço da correia, o lugar do cercado onde se prende e/ou se recolhe o "gado" humano.

A arquitetura escolar, contudo, pode ser de forma dialética parceira e componente de um currículo emancipador. Consideramos a base técnica como um dado de princípio da arquitetura escolar. Sobre esta base, que se pretende 'dada', é necessário perceber e discutir a Responder corretamente às necessidades de dimensionamento, iluminação, ventilação, uso correto de revestimentos, aproveitamento de iluminação e ventilação naturais, entre outras questões técnicas, é apenas a "base" sobre a qual se constituirá a arquitetura como elemento simbólico. A arquitetura escolar reflete, dessa forma, a relação entre as múltiplas possibilidades do espaço escolar, sob a forma de arquitetura, e as diferentes visões e propostas curriculares. Em suma, para cada projeto político pedagógico escolar corresponde uma ou algumas concepções específicas de arquitetura - eis a questão que tem passado em branco nas discussões tanto na área de arquitetura quanto na de educação-pedagogia.

O desenvolvimento de pesquisas, sob esse prisma, que articulem as leituras pedagógicas e o referencial da Formação Humana Omnnilateral - com o levantamento da arquitetura escolar, cotejando-a com estudos complementares acerca do caráter educativo da arquitetura e do espaço, mormente dos edifícios escolares existentes, podem propiciar mais esclarecimentos e apontar caminhos sobre a temática. Que se inicie o debate !

\section{REFERÊNCIAS BILIOGRÁFICAS}

. ALTHUSSER, Louis. Ideologia e Aparelhos Ideológicos de Estado. 3 Ed. Lisboa, Editorial Presença, 1980. 
. AMARAL, Cláudio. As Teorias Administrativas e o Lay-out. Design \& Interiores, São Paulo, Projeto Editores Associados 2(10), 1988.

. ARRAIS NETO, Enéas. A Arquitetura do Poder e o Poder da Arquitetura. Dissertação de Mestrado em Sociologia - Universidade Federal do Ceará, 1989.

- ARRAIS NETO, Enéas. Arquitetura - Meio de Comunicação de Massa e Direcionamento de Consumo. Revista (Escola Técnica Federal do Ceará), Ano XIX, N 19, pp 83-94. Fortaleza, ETFCE, 1992.

. FOUCAULT, Michel. Vigiar e Punir: História da violência nas prisões. Petrópolis: Vozes, 1997.

- FRAGO, Antonio Viñao, e Augustin ESCOLANO. Currículo, espaço e subjetividade: A arquitetura como programa. 2. Rio de Janeiro: DP\&A, 2001.

. FRANÇA, Lilian C.Monteiro. Caos - Espaço - Educação. São Paulo, Ed. Anna Blume, 1994.

. FURTADO FILHO, José da Rocha. Architectural Meaning. Milwaukee, University of Winsconsin, 1979, Dissertação de Mestrado.

. GIROUX, Henry. Ideologia, cultura \& escolarização. In: Teoria Crítica e resistência em educação. Petrópolis, Vozes, 1986.

. HARVEY, David. A condição pós-moderna. São Paulo, Loyola, 2012.

. MARCUSE, Herbert. A Ideologia da Sociedade Industrial. Rio de Janeiro, Zahar, 1973.

. MARX, Karl \& ENGELS, Friedrich. A Ideologia Alemã. In: FERNANDES, Florestan (org); Marx e Engels: História. São Paulo, Ática, 1983. 
. MENEZES, Eduardo Diatahy Bezerra de. Notas sobre Arquitetura como comunicação de massa. In VIEIRA, Amaral (org): Comunicação de Massa: o impasse brasileiro. Rio de Janeiro, Forense-Universitária, 1978.

. MESMIN, Georges. L'enfant, l'architecture et l'espace. Tournai: Casterman, 1973.

. MOUSSATCHÉ, Helena. A arquitetura escolar como representação social de escola. Rio de Janeiro: UFRJ, 1998.

. NIEMEYER, Oscar. A forma na Arquitetura. Rio de Janeiro, Ed. Revan, 2005.

- OLIVEIRA, Manfredo Araújo. A ética das Ideologias. In: A hora da Ética Libertadora. São Paulo, Paulinas, 1985.

. SAID, Ismail. Architecture for Children: Understanding Children Perception towards Built Environment. Malásia: Universiti Teknologi Malaysia, 2007.

. VEBLEN, Thorstein. Teoria da Classe Ociosa. São Paulo, Abril, 1985 (Coleção: Os Pensadores).

. ZEVI, Bruno. Saber ver a Arquitetura. São Paulo: Martins Fontes, 2002.

\footnotetext{
${ }^{1}$ Arquiteto (UFC), Mestre em Sociologia (UFC), Doutor em Educação (UFC-IOE/Univ.of London), PósDoutor em Filosofia da Arte e Subjetividade (E.H.E.S.S.- Paris); Prof. Associado da Universidade Federal do Ceará; Lider do LABOR - Laboratório de Estudos do Trabalho e Qualificação Profissional-UFC.

${ }^{2}$ Arquiteto (UNIFOR), Pesquisador LABOR - Laboratório de Estudos do Trabalho e Qualificação Profissional - UFC

${ }^{3}$ Arquiteto (UFC), Especialista em Engenharia de Segurança do Trabalho (UNIFOR), Mestre em Políticas Públicas e Sociedade (UECE), Doutor em Educação (UFC); Professor da Universidade de Fortaleza UNIFOR; Bolsista Hora Pesquisa - UNIFOR.
}

RECEBIDO EM: Setembro de 2016

APROVADO EM: Dezembro de 2016 